\title{
Contingent effects of firm and employee reputations on professional advice adoption
}

\author{
Eugene Soon Lee Kang'
}

Received: 3 September 2015/Accepted: 8 April 2016/Published online: 16 April 2016

(C) Springer-Verlag Berlin Heidelberg 2016

\begin{abstract}
Applying resource-based theory and signaling theory, we argue that firm and employee reputations affect consumer adoption of advice offered by professional service providers, and these effects are contingent on contextual variables. Our study on brokerage reports in Singapore supports our arguments. We show that reliance on firm (employee) reputation when adopting advice is higher (lower) if the evaluation of an entity is an initial rather than a repeated one. Also, reliance on employee reputation increases with stronger recommendation or when the entity has a business relationship with the advice-giving firm. These findings have implications for advice-giving firms and policy makers.
\end{abstract}

Keywords Professional service - Firm reputation - Employee reputation · Resource-based theory $\cdot$ Signaling theory

\section{Introduction}

Many professional service providers offer services to consumers in the form of evaluating a third party and giving advice about it. The entity can be an individual, a product, an organization, or a country. For example, expert reviewers write reports and provide consumers with ratings on various products and services, such as

Shun Yin Lam

asylam@ntu.edu.sg

Eugene Soon Lee Kang

aslkang@ntu.edu.sg

1 Strategy, Management and Organization Division, Nanyang Business School, Nanyang Technological University, Nanyang Avenue, Singapore 639798, Singapore

2 Institute on Asian Consumer Insight and Marketing and International Business Division, Nanyang Business School, Nanyang Technological University, Nanyang Avenue,

Singapore 639798, Singapore 
smartphones and movies. Analysts examine companies' financial performance and provide investors with buy/hold/sell recommendations of securities issued by companies. Professional advice adoption can benefit the advisor, the advice recipient, as well as the entity evaluated. For instance, adoption of analyst reports can bring in business for brokerage firms, generate profit for customers, and increase the demand for stocks and bonds.

Few studies have examined the adoption of professional advice, and these are largely confined to healthcare services (Seiders et al. 2015; Spanjol et al. 2015). In the healthcare context, the advice recipient (the patient) is also the evaluated entity and the service provider (e.g., the doctor) interacts with the advice recipient (the patient) before giving advice. Thus, healthcare services are very different from services in which the evaluated entity is not identical with the recipient and the provider has no or little interaction with the recipient. Services of the latter kind are numerous, including expert review, securities rating, accreditation of businesses, and financial auditing, but these contexts have been largely ignored in current studies. Hence, our research contributes to the extant literature by extending our understanding of professional advice adoption into service settings where the evaluated entity is not identical with the recipient of the advice.

Previous research studies have examined a variety of factors affecting advice adoption-including characteristics of the advisor, the advice recipients, and the advice-advisor-recipient interactions, and cues that remind recipients of the advice (Bonaccio and Dalal 2006; Sniezek et al. 2004). However, these studies have not investigated reputations of the advice-giving firm and employee as drivers of professional advice adoption. In making the adoption decision, recipients of professional advice will assess the reliability or quality of the advice given to them. Often professional advice does not possess tangible attributes that enable ex-ante assessment, and therefore advice recipients are likely to refer to firm and employee reputations, which can serve as quality signals of the advice. As such, the two reputation constructs are likely to impact the adoption significantly, and we examine their effects closely in this study.

Firm reputation has received extensive attention in marketing and management studies (Jeng 2011; Parasuraman et al. 1985; Roberts and Dowling 2002). Firm reputation is the global evaluation made by external stakeholders on how well the firm has done in the marketplace (Roberts and Dowling 2002). In parallel with firm reputation, reputation of employees has also received significant attention among researchers and managers. Employees play a central role in shaping the corporate reputation of service firms (Olmedo-Cifuentes et al. 2013). Similar to firm reputation, employee reputation is shown to contribute to service firms' performance (Clarke et al. 2007). Some studies have estimated both the effects of firm reputation and employee reputation (Clarke et al. 2007; Fang and Yasuda 2009). However, these studies are primarily concerned with the effects of employee reputation, treating firm reputation as a control or auxiliary variable in the data analysis. Therefore, we know little about how firm reputation differs from employee reputation as a quality signal. Also, we do not know whether recipients of professional advice would utilize the two kinds of reputation differently when evaluating professional advice. 
Our research addresses the aforementioned knowledge gap. Conceptually, we distinguish the two reputation constructs on the basis of the qualities that they reflect. Empirically, we demonstrate their different effects on professional advice adoption, thus attesting to the distinct nature of firm and employee reputations, and their roles as quality signals in advice adoption. Invoking resource-based theory (RBT), we posit that firm reputation and employee reputation are based on different kinds of assets (tangible or intangible) and capabilities of a service firm, and therefore indicate different qualities of the firm. Furthermore, employing signaling theory (Connelly et al. 2011), we argue that they can serve as quality signals in service evaluation but their credibility as quality signals varies with certain contingencies in the signaling environment. This is because their underlying qualities can be more, or less, relevant to the evaluation under particular circumstances. Therefore, they exhibit different effects when a contextual contingency favors the application of one signal over the other in service evaluations.

We test our research hypotheses on recipient adoption of analyst recommendation found in brokerage reports on publicly listed firms. The stock rating data that we use for hypotheses testing were collected from brokerage reports of firms listed in the Singapore Exchange (SGX), a major securities exchange center in Asia. Stock rating is provided primarily in the form of a report, not requiring direct interactions between the advice giver and the advice recipient. We focus on stock rating in our empirical investigation because the lack of direct interactions provides an appropriate context to examine whether customers rely on firm and employee reputations as quality signals. Our choice of stock rating as the advice under study allows us to examine the effects of both reputation constructs simultaneously because a stock rating report is typically prepared by an analyst working in a brokerage firm, and the names of the analyst and the firm are disclosed in the report. Our choice is also justified in view of the significant contribution that the financial service sector makes to the economy in the intelligence age (Lee et al. 2007).

In the remainder of this article, we first describe RBT and signaling theory as the theoretical perspectives guiding our hypotheses development. Next, we formulate our research hypotheses and present our empirical results in the context of stock ratings. After describing our findings, we discuss the contributions of this paper to knowledge, management practice and public policy, as well as limitations and possible extensions of this paper.

\section{Theoretical background}

\subsection{Resource-based theory}

Resource-based theory (RBT) emphasizes the role that organizational resources play when firms seek to gain a sustainable competitive advantage over their rivals (Barney 1991; Dierickx and Cool 1989). The theory has been applied to customerseller dyads and interfirm relationships to explain the effect of exchange-level resources on exchange performance and the contingent factors that affect this linkage (Kozlenkova et al. 2014; Palmatier et al. 2013). From the RBT perspective, 
both firm reputation and employee reputation can be conceptualized as organizational resources.

Firm reputation is an intangible asset with the potential to create sustainable advantage (Barney 1991; Roberts and Dowling 2002). One determinant of firm reputation is the synergistic integration of firm resources to produce quality reports by professional service firms (Boyd et al. 2010). For example, the human capital of analysts in a brokerage firm is likely to be a key determinant of firm reputation. Other resources may include a firm's information/knowledge databases, administrative staff that handles client-related activities, and the firm's distribution network to disseminate reports to service recipients (Clement 1999; Groysberg and Lee 2008; Stickel 1995). How well a service firm integrates various resources to produce and disseminate quality reports to service recipients on a timely basis creates an intangible asset. In short, firm reputation is not only an overall evaluation of the firm by the market but also an indicator of the valuable resources and capabilities possessed by the firm.

Employee reputation is also a market-based resource as it is derived from the market's evaluation of individual employees. While firm reputation is derived from the synergistic integration of complementary resources within a firm, an employee's reputation is largely determined by the human capital of the employee. Human capital is defined as "an individual's cumulative abilities, knowledge, and skills developed through formal and informal education and experience" (Pil and Leana 2009 , p. 1103). For example, the human capital of an employee comprises the stock of knowledge that she (or he) has accumulated about a company under evaluation and its industry because such knowledge increases the accuracy of earnings estimates and valuation of the company in a brokerage report (Dierickx and Cool 1989). In other words, employee reputation indicates an employee's possession of knowledge that is specific to certain companies or industries.

In sum, firm and employee reputations are intangible market-based resources that are associated with different assets and capabilities. The assets or resources underlying firm reputation are generic in that they are applicable to different entities. In contrast, the cumulative abilities and knowledge underlying employee reputation are specific to particular entities or sectors that have been covered by employees. These abilities and knowledge do not lose their value when an employee moves to another firm. In other words, they are not specific to the firms that hire the employee.

There is empirical evidence to support RBT's prediction that the reputations of a service firm and its employees are valuable resources considered by service recipients when evaluating a firm's services. For instance, Parasuraman et al. (1985) identified firm reputation as a key factor contributing to service recipients' perceived credibility of a service in question. Firth (1990) showed that when the works of audit firms are criticized, these firms incur economic losses from damaged reputations. Furthermore, consistent with RBT's prediction, there is evidence that the reputation of employees impacts firm performance positively in various settings (Zajac and Westphal 1996). Studies that simultaneously examine the impact of service firm and employee reputations are rarer. In general, these studies found that service firm and employee reputations do not necessarily have the same impact on 
marketing outcomes (Clarke et al. 2007; Yim et al. 2008). For example, Clarke et al. (2007) found that analyst reputation and bank reputation have different impact on the market shares of different services offered to clients.

Although the RBT explains how firm reputation and employee reputation are conceptually different, its sole application cannot fully explain how these reputation constructs are related to service evaluation and how this relationship is affected by contingencies. We therefore apply signaling theory to complete the explanation.

\subsection{Signaling theory}

Signaling theory recognizes the impact of imperfect information on the behavior of economic actors and posits that economic actors seek to reduce information asymmetry in economic transactions (Connelly et al. 2011). The theory has been adopted in a wide range of disciplines (Calderon-Monge and Huerta-Zavala 2014; Kang 2008; Riley 2001). It provides a useful lens to explicate how distinct marketbased resources, such as firm reputation and employee reputation, matter for the exchange outcomes of firms with service or knowledge-based offerings. A fundamental characteristic of service firms is the intangibility of the offerings (Berry 1980). According to Zeithaml et al. (1985), "services are performance, rather than objects, they cannot be seen, felt, tasted, or touched in the same manner in which goods can be sensed" (p. 138). Under such conditions, the information asymmetry between buyers and sellers renders ex-ante evaluations of the service quality ambiguous (Bishop and Megicks 2002). Studies have shown that when exchange transactions are characterized by high levels of information asymmetry, buyers rely on signals that provide credible proxies of quality indicators to combat adverse selection problems, which are about the likelihood of purchasing less desirable products (Dawar and Parker 1994; Li et al. 2009). In particular, there is evidence that reputational assets provide credible signals of quality for firms (Dawar and Parker 1994).

Although recipients of service offerings may rely on reputational assets as signals of quality, the credibility of these signals is not necessarily invariant. In fact, signaling theory recognizes that the strength of signals may vary with the signal fit, which is defined as the extent to which a signal is correlated with, or represents a valid and reliable measure of, the unobservable quality being signaled (Connelly et al. 2011). For instance, Schijven and Hitt (2012) found that the fit of acquisition premiums as a valid and reliable signal of the synergistic potential of an acquisition is contingent on contextual factors.

The above arguments suggest that in adopting professional advice, recipient reliance on the signals emanating from firm and employee reputations is determined by the signal fit, i.e., the extent to which consumers perceive these signals as reflecting the quality of the advice offered by a service provider. Contingencies affecting the signal fit may sway consumers to increase or decrease their reliance on either reputation type. For instance, while high brokerage firm and analyst reputations may signal high brokerage report quality and increase the confidence that recipients place on the stock recommendation, the signal fit between these reputation types and report quality may be weakened or strengthened by 
contingencies in the signaling environment. These contingencies include details of the evaluation context or content which inform recipients of the service firm's or the employee's intentions or effectiveness in deploying their resources. For example, conflicts of interest arising from a business relationship between a service firm and an entity under evaluation may make recipients wonder whether the firm would faithfully publish unbiased evaluations. Recipients may also perceive that an employee giving strong advice on an evaluated entity may possess substantive and credible knowledge of the entity in support of the advice.

For our research, we choose the following contingencies: (1) the business relationship that exists between the service firm and the entity covered in the report; (2) the strength of professional advice contained in the evaluation report; and (3) whether the report is the initial evaluation of the entity in question (e.g., the firsttime assessment of the entity) or a repeated evaluation. These choices are made on the basis of the following considerations. First, we want to cover both types of contingencies that affect service recipients' reliance on firm reputation and employee reputation, respectively. Second, these contingencies have practical significance and draw recipients' attention. Conflicts of interest are cited as the most frequent violations of professional conduct (Gillis and Earp 1979), and business relationship is a common cause giving rise to conflicts of interest. Business relationship became a serious concern when several corporate scandals involving conflicts of interest broke out in the U. S. in the first half of this century (e.g., the Enron Scandal in 2001 and the collapse of Lehman Brothers in 2008). Past studies have also shown that recipients pay attention to the strength of professional advice (e.g., a target price for a stock under evaluation) and to whether an evaluation is an initial or a repeated type (Barber et al. 2001; Irvine 2003). Furthermore, the strength of professional advice and evaluation type (i.e., initial or repeated) are likely to capture attention because this information is prominently displayed in an evaluation report. Third, the choices of these contingencies allow us to reveal the different characteristics and bases of firm and employee reputations, and hence provide conceptual insights. For example, resources contributed by service firms to evaluation services are more generic and portable across the covered entities whereas the knowledge and experience applied by employees to the services are more specific to the entities. The implication of this difference becomes apparent when the signaling environment directs attention to the accumulated knowledge of employees about a covered entity (e.g., when the evaluation of the entity is a repeated one). Fourth, the contingencies apply to a variety of professional services. For example, business relationship is a concern in auditing, stock rating, and accreditation of businesses. Repeated evaluations of the same entity are also common for these professional services.

\subsection{Firm-entity business relationship}

A plausible condition that changes the signal fit between firm (or employee) reputation and report quality is the presence of a publicly disclosed business relationship that exists between the service firm providing the advice and the covered entity. Conflicts of interest arising from business relationships involving 
professional service firms took center stage in the U.S. in the first decade of this century when the public knew about the relationships. For example, some financial services firms (e.g., Credit Suisse First Boston, Lehman Brothers) offered both research and investment banking services, and the stock recommendations offered by their research departments were tainted by business relationships that their investment arms had with the companies covered by the recommendations (Siow 2002). Because the process of securities analysis cannot be observed by investors, opportunities exist for financial services firms to provide biased reports when they are motivated to do so (Cote and Goodstein 1999; Jennings 2005). The tainted recommendations in the example helped increase the sales of the stocks underwritten by the financial services firms. Although giving biased advice could damage the reputation of these firms, the prospect of substantial commission gain from the increase in the sales of the stocks overrode this concern. Similarly, private institutes conducting university rankings were criticized because these institutes were suspected of targeting universities that had business relationships with them (Holmes 2006). Generally speaking, service recipients could be aware that in the presence of a business relationship, the service firms may try to bias the recommendations - e.g., by exerting pressure on their employees to produce biased reports. Therefore, they trust the service firms less and rely less on firm reputation when considering recommendations provided by these firms.

Would service recipients also regard employee reputation as unreliable in the presence of a business relationship? We argue that recipients' reliance on employee reputation would not decrease or may even increase in the presence of the business relationship. First, recipients are unlikely to perceive that individual employees can directly benefit from such a relationship. Second, professional service employees exercise care to protect their reputation. For example, analysts' compensations and career prospects are often dependent on their reputations (Baldwin and Rice 1997; Hong and Kubik 2003). Because investors can cheaply monitor the recommendations of analysts on their forecast accuracy (Jackson 2005), analysts are motivated to provide accurate forecasts in order to enhance or maintain their reputation. Third, employee reputation is not necessarily specific to the firm hiring the employee as an employee's skills and knowledge can be transferred across firms without significant loss in value. For instance, we expect analyst reputation to exhibit low brokeragefirm-specificity because analyst reputation is related to an analyst's ability to produce good quality estimates and forecasts, which are largely derived from her/his stock of accumulated knowledge on the covered firms (Dierickx and Cool 1989). Hence, an employee's reputation is a valuable asset to her, allowing her to move to and negotiate compensation with other firms. In sum, the foregoing considerations make a reputable employee unlikely to compromise on the accuracy of her recommendations (Coff 1999). This is also corroborated by empirical evidence against allegations that reputable analysts have helped generate investment banking deal flow by issuing overly positive recommendations (Clarke et al. 2007). By comparison, an employee with low reputation is more likely to provide biased advice when she is under pressure from the service firm, because she has little or no tangible benefit to lose in doing so. Therefore, the difference between a reputable employee and a less reputable one can increase in the presence of a 
business relationship. This is supported by Fang and Yasuda (2009), which shows that the gap in forecast accuracy between reputable analysts and less reputable analysts widened in periods of high underwriting volumes (when the potential of conflicts of interest is high). If advice recipients perceive this widening gap in the presence of a business relationship, they will rely more on employee reputation in service evaluation. The foregoing discussion leads us to advance:

H1a The effect of firm reputation on professional advice adoption will decrease when the covered entity has a publicly disclosed business relationship with the service firm than when it has not.

H1b The effect of employee reputation on professional advice adoption will increase when the covered entity has a publicly disclosed business relationship with the service firm than when it has not.

\subsection{Strength of advice}

Another plausible factor that reinforces the signal fit between employee reputation and report quality is the strength of advice. The strength of advice refers to the extremity of the professional advice given to the recipient. For example, an extremely high or low rating of a covered entity (e.g., a business, a bond, or a movie) indicates strong advice. According to RBT, a strong recommendation suggests that an employee performing the evaluation is able to utilize her knowledge and ability to differentiate a covered entity from other entities in the same category, and thereby make a bold statement about the former (Dierickx and Cool 1989). Additionally, in the case of stock recommendations, strong advice sends a signal that an analyst is privy to important information or knowledge of a covered firm that has yet to be incorporated into the stock price. Evidence from securities data analysis also supports the claim that analysts' forecasts contain valuable private information about the covered firm (Dimson and Marsh 1984). Hence, bolder estimates of target prices that differ significantly from current prices are likely to engender a stronger reliance on analyst reputation as a signal for quality reports.

By comparison, we posit that strong advice weakens the signal fit between service firm reputation and advice quality. Recall that RBT regards firm reputation as generic, being determined by the overall experience of its customers, and having less to do with the human capital of a particular employee. Since strong advice is primarily based on an employee's human capital, advice recipients are more likely to relate the strength of advice to the employee than to the service firm. Furthermore, research in human decision-making suggests that the amount of attention which people pay to a particular decision criterion affects the impact of this criterion on a focal decision (Busemeyer and Townsend 1993; Roe et al. 2001). Related arguments and evidence about the attention-impact connection can be found in the literature that discusses price as an extrinsic quality cue (i.e., a quality signal) for product evaluation. Researchers propose that additional extrinsic cues (e.g., store name and brand name) may make consumers rely less on price information for 
product quality judgments (Dodds et al. 1991; Monroe and Dodds 1991). Dodds et al. (1991) provide corroborative evidence that the price-quality relationship is diminished in the presence of a brand name or a store name. In other words, the relationship is stronger in the absence of other quality cues. The finding that consumers pay greater attention to a quality cue in the absence of other cues supports the argument that greater attention to a cue can enhance the impact of the cue on quality judgments. The argument is also consistent with the findings of other scholars who study the effect of signals generated through organizational affiliations with other entities (Khoury et al. 2013; Ozmel et al. 2012). When recipients perceive employee reputation as a stronger quality signal, they may pay greater attention to it and devote less attention to other signals. As a result, the impact of firm reputation on recipient adoption of professional advice could be weakened when the advice is of the strong type. Therefore, we advance:

H2a The effect of firm reputation on professional advice adoption will decrease when the advice is strong than when it is not.

H2b The effect of employee reputation on professional advice adoption will increase when the advice is strong than when it is not.

\subsection{Initial evaluation}

A third factor which may affect the signal fit between employee reputation and advice quality concerns whether the evaluation conducted by an employee is an initial assessment of the covered entity (i.e., a first-time assessment). Some professionals (e.g., auditors, analysts, and counselors) provide advice recipients with repeated evaluations on the same entity over time. An employee's understanding of the entity's conditions can grow over repeated evaluations. Earlier, we highlight that RBT conceptualizes employee reputation as an indicator of knowledge-based assets accumulated by the employee over time. For example, the ability of an analyst to produce quality reports is largely dependent on the stock of knowledge assets that is relevant to a covered firm. From the RBT perspective, the stock of knowledge assets that an analyst has is largely determined by the amount of investments made to research a firm and its relative competitive position in the industry (Dierickx and Cool 1989). Hence, there is a premium to the gradual accumulation of knowledge over time as the incremental flow of knowledge gained with each additional research adds to the knowledge stock and improves the ability of an analyst to make more accurate forecasts about the covered firm (Mikhail et al. 1997). Furthermore, the RBT literature emphasizes the internal sources of firm heterogeneity. If a covered firm is indeed a unique ecosystem of resources that are linked by means of pathdependent organizational routines (Nelson and Winter 1982), knowledge of what constitutes the firm's core competencies provides little value in understanding the core competencies of other covered firms. Therefore, what matters more to recipients is an employee's prior experience in evaluating an entity when they consider the quality signal emanating from the employee's reputation. In short, these RBT arguments posit that employee reputation would not be a good predictor of report 
quality in the initial evaluation as knowledge of an entity's conditions would be limited at this point. In contrast, recipients would perceive employee reputation as a stronger signal of report quality for subsequent evaluations.

Unlike employee reputation, firm reputation has a broader relationship with advice quality, spanning across both initial and subsequent evaluations of an entity. For instance, brokerage firm reputation is more generic and portable across covered entities since it is based on the synergistic integration of resources that enables a firm to produce quality reports. A recipient's perception of a firm's services is therefore likely to be broad and not limited to a specific covered entity. Hence, firm reputation is largely dependent on the overall experience of its customers with the quality of its reports as a whole. Furthermore, if recipients discount employee reputation when reacting to the advice given, they may pay greater attention to firm reputation as a quality signal (Busemeyer and Townsend 1993; Khoury et al. 2013). As a result, we expect recipients to compensate for a lower reliance on employee reputation with a higher reliance on firm reputation when reacting to initial evaluation. In sum, we put forward:

H3a The effect of firm reputation on professional advice adoption will increase when the evaluation of the covered entity is initial than when it is not.

H3b The effect of employee reputation on professional advice adoption will decrease when the evaluation of the covered entity is initial than when it is not.

To sum up, by invoking several theories (most notably, the RBT and signaling theory), we put forward six hypotheses about the effects of three moderators (business relationship, strength of advice, and initial evaluation) on the associations between firm/employee reputations and recipient adoption of professional advice.

\section{Method}

\subsection{Data collection}

We test our hypotheses on recipient adoption of professional advice found in brokerage reports on publicly listed firms. A brokerage report is written by an analyst from a brokerage firm and offers investment advice on the shares of a listed firm. The primary advantage of testing our hypotheses in this context is that we can capture recipients' adoption of the professional advice in the market and study the effects of firm reputation and employee reputation simultaneously.

We restrict our sample to brokerage reports published under the SGX-MAS Research Incentive Scheme on firms listed in Singapore. The results of this study have important implications because Singapore is not only a major financial center in Asia (Huat et al. 2004) but its stock market capitalization is also ranked first among the ten member countries in the Association of Southeast Asian Nations (ASEAN), followed by Malaysia and Thailand. The SGX, together with the MAS, launched the SGX-MAS Research Incentive Scheme in 2003 to enhance research coverage of stocks listed in SGX. Each brokerage report generated under this 
Scheme covers one SGX-listed firm and is available to the public on the SGX website. Furthermore, the SGX website indicates the publication date of each brokerage report, and the names of the brokerage firm and analyst are clearly indicated in each report.

Our sample consists of brokerage reports published from 2004 to 2006. Although the SGX-MAS Research Incentive Scheme started in 2003, we did not include reports published in 2003 because Singapore (and other parts of Asia) was struggling with the Severe Acute Respiratory Syndrome outbreak that year. The Singapore stock market bottomed out in 2003 albeit with high volatility (the market index registered a standard deviation of 50.4). Similarly, we excluded reports after 2006 because stock market volatility increased significantly from 2007 onward (the market index registered standard deviations of 16.7, 23.0, 41.9, 60.5, and 151.4 from 2004 to 2008). This was followed by a steep decline in the market index following the global financial crisis from the Lehman Brothers debacle in 2008.

We adopted the following five criteria to select brokerage reports into our sample: (1) reports that made buy or sell recommendations, (2) reports written by a single analyst, (3) reports published on a day without any announcements by the covered firms, (4) reports published on a day without reports on the same covered firms published by other brokerage firms, and (5) the first reports on the covered firms during the sample period.

The first criterion excludes hold recommendations because we examine the adoption of advice in brokerage reports, where the strength of recipient reaction is measured by the abnormal stock returns attributed to the brokerage reports since larger returns equate to stronger recipient reaction. Hence, by default, the advice in brokerage reports must recommend recipients to either buy or sell shares in the equity market, and not hold recommendations which do not require recipients to do anything. The second criterion eliminates the problem of measuring analyst reputation (or aggregating individual reputation to group reputation) when reports are written by a group of analysts with different reputation scores. Focusing on reports written by a single analyst allows us to better draw conclusions about the impact of analyst reputation on recipient reactions.

The third criterion is required so that recipient reaction to a brokerage report could be solely attributed to the publication of the report and not to confounding announcements by the covered firm (McWilliams and Siegel 1997). Similarly, the fourth criterion is required so that the reaction may be solely attributed to the reputations of one analyst and one brokerage firm rather than multiple analysts and brokerage firms (McWilliams and Siegel 1997). In addition, given that an analyst might publish more than one brokerage report on a firm over the sample period, we included the fifth criterion to avoid violating the independence assumption. Selecting the first brokerage report during the sample period does not imply that only initiation reports (initial evaluation) are selected since reports that initiated coverage may have been published prior to the sample period.

The final sample comprises 339 brokerage reports published by 135 analysts from 13 brokerage firms and consists of 273 reports with buy recommendations and 66 reports with sell recommendations. 


\subsection{Dependent variable: recipient adoption of professional advice}

Financial-event study methodology has been used to compute abnormal returns when examining how a firm's value reflected by its stock price is influenced by events such as brand acquisition and disposal (Wiles et al. 2012). The same methodology may also be used to compute abnormal returns (AR) to measure recipient reaction that reflects recipient adoption of advice given in brokerage reports. AR unambiguously captures whether recipients respond in a manner that is consistent with a report's recommendation. For instance, a buy (or sell) recommendation suggests that the current stock price is undervalued (or overvalued). Recipient adoption of the recommendation will lead to an increase (or decrease) in stock price, which is captured by a positive (or negative) AR in the event window. Another benefit is that the magnitude of the AR unequivocally measures the strength of recipient reaction as larger absolute values of the AR equate to stronger reactions.

We define the event window as a 2-day period that comprises 1 day prior to and the day of publishing the brokerage reports. The 2 days are used because financialevent studies assume that efficient markets will quickly incorporate financially relevant information into stock prices (Wiles et al. 2012). The day prior to the publication is included to account for leakage of information before the event (McWilliams and Siegel 1997). We did not extend the event window to include 1 day after publication as the market would have priced in the recommendations on the day of publication, given that these reports are typically published at the beginning of or during the trading day. Furthermore, we found that the AR estimated 1 day after publication was not significant for sell recommendations. A review by Dimson and Marsh (1984) also highlights the absence of systematic abnormal returns 1 day after stock recommendations. The computation of AR is described in "Appendix."

We derive the ARs for each day in the event window and then sum the ARs to arrive at the cumulative abnormal returns (CAR), which we use as a measure of recipient reaction to the report. To test our hypotheses, we multiply the CARs for reports with sell recommendations by -1 so that positive values now represent consistent recipient reaction to sell recommendations while negative values represent otherwise. There is no need to transform the CARs for reports with buy recommendations since positive (negative) values already represent consistent (inconsistent) recipient reaction to buy recommendations.

\subsection{Independent variables of interest}

Our study has five independent variables of interest, including firm and employee reputations, and three moderator variables, namely, business relationship, strength of advice, and initial evaluation. First, firm (brokerage) reputation is measured using two approaches. The first approach adopts the StarMine rankings of Singapore brokerage firms. StarMine, a Thomson Reuters firm, provides objective equity research performance ratings that help investors make better decisions. StarMine ranks the top ten Singapore brokerage firms, with the top (first) spot going to the firm whose buy/sell recommendations result in the highest returns and have the most 
accurate earnings estimates. These rankings are published in The Business Times, a premier business newspaper in Singapore. For hypothesis testing, we reverse coded the ranks such that firms ranked at the top have a higher reputation score while those at the bottom have a lower score. For instance, after the coding, the first (top) brokerage firm has a reputation score of ten while the tenth (bottom) firm has a score of one. Brokerage firms not in the top ten rankings are assigned a score of zero.

The second approach measures firm reputation by surveying an expert panel of ten finance professionals (Goes and Park 1997). Through the lead author's contacts, we identified and spoke to a senior manager of a foreign financial services firm in the securities industry with a local office in Singapore. We briefed the manager on the objectives of the research project and obtained his support to survey his staff in exchange for a summary report of our study results. A total of ten finance professionals, holding appointments such as fund managers and investment advisors, were hand-picked to participate in the survey. These experts were chosen because they handle brokerage reports on a regular basis and lack business-related ties to the brokerage firms included in the survey.

Each survey participant was given a survey form which lists all 13 brokerage firms that participate in the SGX-MAS Research Incentive Scheme. Firm reputation is defined in the survey as the perception of a firm's ability, relative to its competitors, to create value for investors by providing them with information to facilitate their investment decisions. Each participant indicated their response to the following statement on a 5-point Likert scale for each brokerage firm: "The brokerage firm produces quality research reports." A score of 5 indicates strong agreement with the statement while a score of 1 indicates strong disagreement. The average score for each brokerage firm across all ten surveys was computed to arrive at a reputation score. We conducted separate analyses using both measures of firm reputation. Since the results of the hypotheses testing are substantively similar, for brevity, we only present the results based on the survey measure.

Second, we use the StarMine rankings of analysts covering SGX-listed firms to measure employee (analyst) reputation. Annual rankings of analysts from thirdparty sources, such as the Institutional Investor Survey, have been used as a proxy for analyst reputation (Clarke et al. 2007). Since the Institutional Investor Survey does not include analysts covering SGX-listed firms, we obtained ranking data from StarMine, which uses its equity analyst performance data to rank the top analysts according to stock recommendation performance and estimation accuracy. These rankings are also published in The Business Times. Similar to the coding of firm reputation, we reverse coded the ranks such that analysts ranked at the top will have a higher reputation score while those at the bottom will have a lower score. Analysts that are not in the rankings are assigned a reputation score of zero. We also conducted a robust analysis using a dummy variable since prior studies have used such a measure (Clarke et al. 2007). Specifically, the dummy variable is coded as one if an analyst is listed in the StarMine rankings, and zero otherwise.

Third, business relationship is a two-level categorical moderator variable. A brokerage firm has a business relationship with a covered firm if it previously participated or is part of a larger entity, such as a financial institution, that participated in the covered firm's public equity offerings since listing. This 
information is extracted from the SDC database by Thomson Reuters, which compiles publicly available information on financial transactions in equity capital markets. We followed the recommendation of Irwin and McClelland (2001) and adopted contrast coding whereby the presence and absence of a business relationship is coded as 1 and -1 , respectively. The advantage of using contrast coding is that the reported coefficients for firm and employee reputations in our statistical analysis represent their main effects averaged over the levels of business relationship in the sample because the mean contrast code is zero. If dummy codes were used, i.e., the absence of a business relationship is coded as 0 instead of -1 , the reported coefficients for firm and employee reputations are less meaningful since they represent the effect of these reputations only in the absence of a business relationship.

Fourth, strength of advice, another moderator variable, is measured by computing the absolute percentage difference between the target stock price and the current stock price as stated in each brokerage report. A larger absolute percentage difference suggests that the firm is more undervalued (for buy recommendations) or overvalued (for sell recommendations) and is likely to provoke stronger recipient reaction to brokerage report recommendations.

Finally, initial evaluation is also a two-level categorical moderator variable. As in the case of business relationship, we applied contrast coding to this variable and assigned a value of 1 if an analyst wrote an initiation report (i.e., first-time assessment) on the covered firm, and a value of -1 otherwise. An initiation report is clearly identified in the report's contents. We also verified that the analyst who wrote the initiation report in the current brokerage firm did not have prior experience covering the SGX-listed firm if she or he was previously employed by another brokerage firm.

\subsection{Control variables}

We included a number of control variables that may affect recipient adoption of professional advice in the empirical model. Some of them capture the characteristics of the covered firms, brokerage reports, analysts, and brokerage firms, whereas others are about information symmetry that recipients may experience, and the report publication years. The data for these variables were extracted from the SGX website, the annual reports of the covered firms, the brokerage reports, or the OSIRIS database by Bureau Van Dijk, which provides financial and non-financial data for listed firms.

Regarding the characteristics of the covered firms, we included firm size (total assets) and performance (return on equity) as control variables (Kumar 2010; Stickel 1995). Several firms in our sample are also family firms listed in the SGX. Hence, we included a dummy variable to control for family effects. This dummy variable was coded as one for family firms, and zero otherwise. We also controlled for founder effects by including a second dummy variable coded as one if the founder is a board member, and zero otherwise. Regarding the characteristics of the brokerage reports, we controlled for variation in recipient reactions to buy or sell 
brokerage recommendations (Diefenbach 1972) by including a dummy variable which was coded as one for buy recommendations and zero otherwise.

We controlled for the extent of information asymmetry that recipients of brokerage reports may experience with regard to firm valuation. Since brokerage firms and analysts strive to reduce information disadvantages for traders (Asquith et al. 2005), recipients who are less informed, i.e., those who experience higher information asymmetry, are likely to react more strongly to the recommendations in brokerage reports as they adjust their price expectations to new information in these reports. Information asymmetry is reduced when a brokerage report contains more information or if a firm is covered by more brokerage firms, listed for a greater number of years, protected by good governance, or located in an environment with low dynamism. Therefore, we used the following variables as proxies for the extent of information asymmetry. First, we controlled for the length of a brokerage report to account for the quantity of information in the report. Some brokerage reports also specify the valuation method used to estimate the fair value of the covered firm, while others do not. Hence, we included a dummy variable coded as one if the valuation method is stated, and zero otherwise. Second, we included the number of brokerage firms that provide stock coverage for the SGX-listed firm and the number of years that the covered firm has been listed. We controlled for years listed instead of firm age because as equity investors, the advice recipients have access to more information on firms with a longer listing tenure, all else equal. Therefore, years listed serve as a better control for uncertainty. Third, we included several measures of governance quality. They are the proportion of independent directors, the presence of an independent board chair (a dummy variable coded as one if the board chair is independent and zero otherwise), and the proportion of equity ownership held by all directors. Finally, we controlled for environmental dynamism, which is the level of environmental uncertainty that a covered firm is experiencing. The environmental dynamism for each covered firm is measured based on the firm's primary industry. We regressed a variable for each year on a variable for net industry sales using the following basic regression model, $y_{t}=\beta_{0}+\beta_{1} t+\varepsilon_{t}$, where $y_{t}$ is the natural $\log$ of the annual net industry sales in a firm's primary industry, $t$ is the year, and $\varepsilon_{t}$ is the residual. Five years of data were used for the regression model-for example, net industry sales from 2000 to 2004 were used to predict environmental dynamism for a firm in 2005. Each firm's primary industry and the net industry sales of all firms in a firm's primary industry were extracted from the OSIRIS database. Environmental dynamism is operationally defined as the antilog of the standard error of the regression slope coefficient $\left(\beta_{1}\right)$ from the basic regression model, where larger values indicate greater environmental dynamism (Kang 2008).

We also controlled for certain characteristics of the analysts and brokerage firms. Data on analysts and brokerage firms are harder to code as most of the brokerage firms are private entities and analyst profiles are not common. Nonetheless, we were able to control for gender effects (Bosquet et al. 2014) by observing the photos and/ or names of analysts in the brokerage reports. We identified whether brokerage firms have local or foreign origins and whether they are listed in the SGX. We also controlled for regulatory actions since studies have shown that illegal acts tarnish 
firm and individual reputations (Efendi et al. 2013; Karpoff and Lott 2005). We searched the Monetary Authority of Singapore website for enforcement actions and news articles for disciplinary actions against brokerage firms and analysts. Our search strategy revealed some regulatory judgments on brokerage firms but did not find any for analysts. Hence, a dummy variable was included to control for regulatory judgments on brokerage firms.

Finally, we included time dummy variables to control for the years that the reports were published, and industry dummy variables to control for potential idiosyncratic industry effects of the covered firms.

\subsection{Statistical analyses}

We employed the multilevel technique described in Rabe-Hesketh and Skrondal (2008) to empirically test our hypotheses. Standard ordinary least squares regression is not suitable since the assumption of independence is violated with a nested (or hierarchical) data structure. Our data have a nested structure because the brokerage reports are grouped into analysts, where each analyst published brokerage reports for more than one SGX-listed firm during the sample period. By comparison, analysts are not grouped into brokerage firms because some analysts left a brokerage firm to join another brokerage firm over the sample period. Therefore, the structure of our dataset is similar to what Rabe-Hesketh and Skrondal (2008) refers to as a cross-classified structure in which the lower-level units (i.e., brokerage reports) are cross-classified by two higher-level units (i.e., analysts and brokerage firms). For instance, an analyst may have written a total of five brokerage reports over the sample period, but three of these reports were written while employed by a brokerage firm, and the other two were written while employed by another brokerage firm. Hence, brokerage reports (the micro units) are nested in analystbrokerage pairs (the macro units).

\section{Results}

Table 1 shows the correlation matrix and descriptive statistics of the variables used in the study, whereas Table 2 shows the results of the cross-classified model using Stata's xtmixed function with maximum likelihood estimation for model fitting as described in Rabe-Hesketh and Skrondal (2008).

Table 2 contains the results of three alternative models, models 1, 2, and 3 . Model 1 includes the control variables only. Model 2 includes these variables plus the independent variables of interest. Model 3 expands Model 2 by incorporating the interactions between the independent variables. All continuous independent variables are centered prior to creating the interaction terms. The significant change in the deviance statistic $\left(\chi^{2}=24.33, p<0.001\right)$ after including the independent variables suggests that model 2 offers a better fit than model 1. Likewise, the inclusion of the interactions in model 3 results in a significant change in the deviance statistic $\left(\chi^{2}=18.46, p<0.01\right)$, suggesting that model 3 performs better than model 2 . We use model 3 to test our hypotheses. 


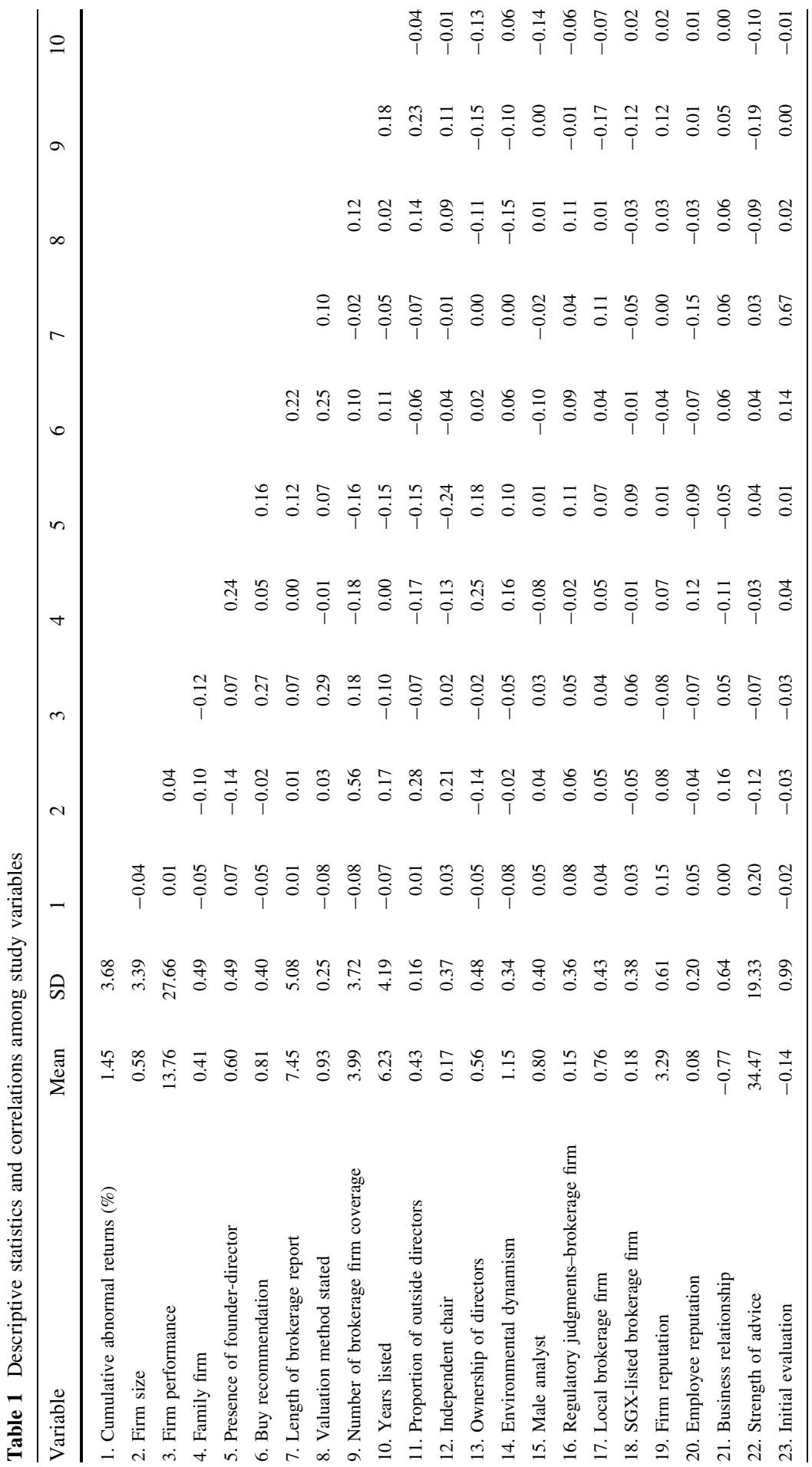







Table 2 Results of cross-classified multilevel model predicting consumer adoption of professional advice

\begin{tabular}{|c|c|c|c|c|c|c|}
\hline \multirow[t]{2}{*}{ Variable } & \multicolumn{2}{|l|}{ Model 1} & \multicolumn{2}{|l|}{ Model 2} & \multicolumn{2}{|l|}{ Model 3} \\
\hline & $\beta$ & SE & $\beta$ & SE & $\beta$ & SE \\
\hline Intercept & 4.65 & 3.36 & 5.14 & 3.29 & 6.86 & $3.23 *$ \\
\hline \multicolumn{7}{|l|}{ Control variables } \\
\hline Firm size & 0.02 & 0.08 & 0.02 & 0.08 & 0.04 & 0.08 \\
\hline Firm performance & 0.00 & 0.01 & 0.01 & 0.01 & 0.01 & 0.01 \\
\hline Family firm & -0.28 & 0.46 & -0.31 & 0.45 & -0.26 & 0.44 \\
\hline Presence of founder-director & 0.96 & $0.48^{*}$ & 0.94 & $0.46^{*}$ & 0.78 & $0.46^{\dagger}$ \\
\hline Buy recommendation & -0.26 & 0.58 & -0.16 & 0.57 & -0.24 & 0.56 \\
\hline Length of brokerage report & 0.00 & 0.04 & 0.01 & 0.05 & -0.03 & 0.05 \\
\hline Valuation method stated & -2.41 & $0.93 * *$ & -2.46 & $0.90 * *$ & -2.57 & $0.88 * *$ \\
\hline Number of brokerage firm coverage & -0.04 & 0.07 & -0.02 & 0.07 & -0.06 & 0.07 \\
\hline Years listed & -0.02 & 0.05 & -0.01 & 0.05 & 0.00 & 0.05 \\
\hline Proportion of outside directors & 0.34 & 1.47 & 0.68 & 1.43 & 0.89 & 1.40 \\
\hline Independent chair & 0.82 & 0.59 & 0.48 & 0.58 & 0.44 & 0.58 \\
\hline Ownership of directors & -0.65 & 0.46 & -0.72 & 0.44 & -0.77 & $0.44^{\dagger}$ \\
\hline Environmental dynamism & -0.46 & 2.50 & -0.73 & 2.42 & -1.81 & 2.37 \\
\hline Male analyst & 0.32 & 0.52 & 0.01 & 0.52 & 0.04 & 0.50 \\
\hline Regulatory judgments-brokerage firm & 0.88 & 0.60 & -0.46 & 0.69 & -0.09 & 0.68 \\
\hline Local brokerage firm & 0.02 & 0.52 & 0.85 & 0.55 & 0.47 & 0.55 \\
\hline SGX-listed brokerage firm & -0.04 & 0.55 & -0.14 & 0.54 & 0.10 & 0.54 \\
\hline \multicolumn{7}{|l|}{ Independent variables } \\
\hline Firm reputation & & & 1.28 & $0.43 * *$ & 1.79 & $0.70 * *$ \\
\hline Employee reputation & & & 0.29 & 1.03 & 2.40 & $1.86^{\dagger}$ \\
\hline Business relationship & & & -0.46 & $0.32^{\dagger}$ & -0.65 & $0.37 *$ \\
\hline Strength of advice & & & 0.04 & $0.01 * * *$ & 0.04 & $0.01 * * *$ \\
\hline Initial evaluation & & & -0.10 & 0.29 & 0.05 & 0.29 \\
\hline \multicolumn{7}{|l|}{ Interaction terms } \\
\hline Business relationship $\times$ firm reputation & & & & & 0.50 & 0.68 \\
\hline Business relationship $\times$ employee reputation & & & & & 3.71 & $1.79 *$ \\
\hline Strength of advice $\times$ firm reputation & & & & & 0.01 & 0.02 \\
\hline Strength of advice $\times$ employee reputation & & & & & 0.12 & $0.06^{*}$ \\
\hline Initial evaluation $\times$ firm reputation & & & & & 0.90 & $0.33 * *$ \\
\hline Initial evaluation $\times$ employee reputation & & & & & -2.33 & $1.04 *$ \\
\hline Year and industry fixed effects & Yes & & Yes & & Yes & \\
\hline Wald $\chi^{2}$ & 37.25 & & $65.24 *$ & & $87.86^{* * *}$ & \\
\hline$R^{2}$ & 0.099 & & 0.161 & & 0.206 & \\
\hline Deviance & 1809.56 & & 1785.23 & & 1766.77 & \\
\hline$\Delta$ Deviance & & & $24.33 * * *$ & & $18.46^{* * *}$ & \\
\hline
\end{tabular}

The study sample consists of 339 brokerage reports from 13 brokerage firms written by 135 analysts. $t$ tests are two-tailed for the control variables and one-tailed otherwise

$\mathrm{SE}=$ standard error

$\dagger, *, * *$, and $* * *$ denote significance at the $10 \%, 5 \%, 1 \%$ and $0.1 \%$, respectively 
Examining the results of model 3, we notice that the coefficient estimate of firm reputation, which represents the main effect of firm reputation on recipient adoption of professional advice, is positive and significant $(b=1.79, p<0.01)$. Similarly, the coefficient estimate of employee reputation is positive and marginally significant ( $b=2.40, p<0.1$ ). Next, we direct our attention to the coefficient estimates of the interaction terms pertaining to our hypotheses. Hypothesis 1a, which suggests that recipients rely less on reputation of the firm providing advice when the covered entity has a business relationship with the firm, is not supported as the interaction between business relationship and firm reputation is not significant $(b=0.50$, $p>0.1$ ). In contrast, we find support for Hypothesis $1 \mathrm{~b}$, which posits that recipients rely more on employee reputation when the covered entity has a business relationship with the firm providing advice. Specifically, Hypothesis $1 \mathrm{~b}$ is supported by a significant positive interaction term between business relationship and employee reputation $(b=3.71, p<0.05)$.

Hypothesis $2 \mathrm{a}$, which posits that recipients rely less on firm reputation when the evaluation report offers stronger buy (or sell) recommendation, is not supported given an insignificant positive interaction term between strength of advice and firm reputation $(b=0.01, p>0.1)$. By comparison, Hypothesis $2 \mathrm{~b}$, which advances that recipients rely more on employee reputation when the report offers stronger buy (or sell) recommendation, is corroborated by a significant positive interaction term between strength of advice and analyst reputation $(b=0.12, p<0.05)$.

We also find support for Hypothesis $3 \mathrm{a}$, which suggests that recipients rely more on firm reputation when the report is an initial evaluation of the covered entity. Specifically, Hypothesis $3 \mathrm{a}$ is corroborated by a significant positive interaction term between initial evaluation and firm reputation $(b=0.90, p<0.01)$. Likewise, we find support for Hypothesis $3 \mathrm{~b}$, which postulates that recipients rely less on employee reputation when the report is an initial evaluation, as indicated by a significant negative interaction term between initial evaluation and employee reputation $(b=-2.33, p<0.05)$.

We follow the procedures suggested by Aiken and West (1991) and provide graphs of the four significant interaction terms in Figs. 1 and 2. Although the various graphs illustrate relationships that are consistent with the supported hypotheses, we conduct an additional test to better understand Fig. 1a, which shows that the association between employee reputation and recipient adoption of professional advice is marginally negative in the absence of a business relationship between the covered entity and the firm providing advice. We conduct a separate test to verify if the negative slope in Fig. 1a is statistically significant. To conduct this test, we change the coding for business relationship from contrast coding to dummy coding so that the coefficient of employee reputation represents its effect in the absence of a business relationship. We reran the empirical model (the full results are available upon request) and note that the coefficient is negative but insignificant. Hence, the test result suggests that employee reputation has no significant effect on recipient adoption of professional advice in the absence of a business relationship. By comparison, in the presence of a business relationship, employee reputation has a significant positive influence on whether recipients adopt the professional advice. 


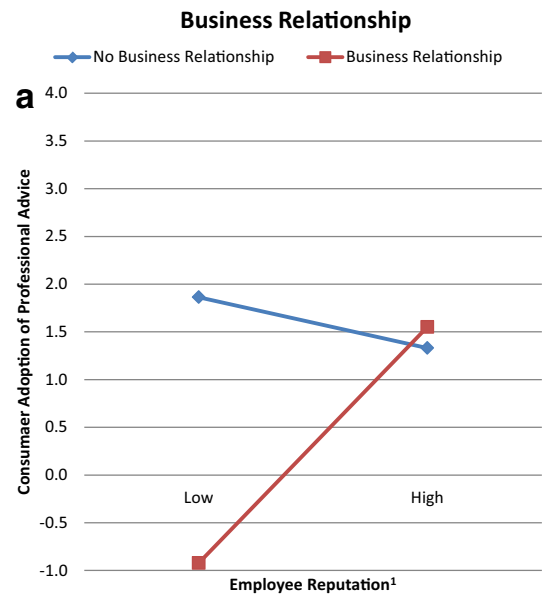

${ }^{1}$ Low and high employee reputation is defined as one standard deviation below and above the mean of the variable.

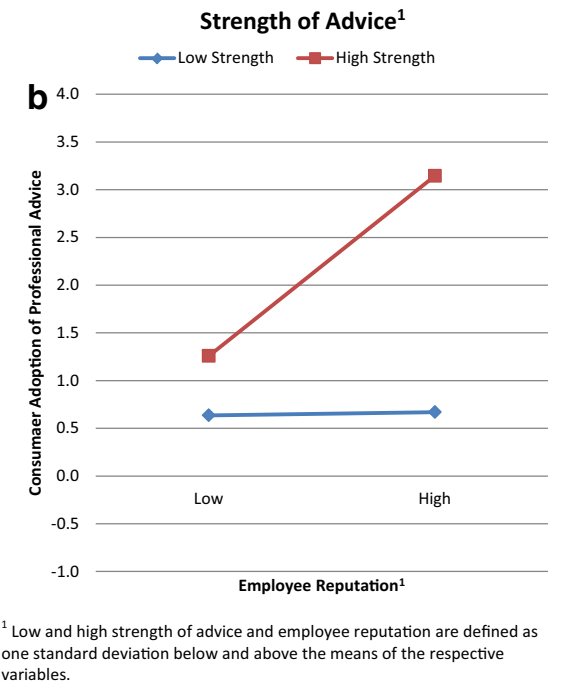
one standard deviation below and above the means of the respective variables.

Fig. 1 a Plot of the relationship between employee reputation and recipient adoption of professional advice for business relationship as the moderating variable. b Plot of the relationship between employee reputation and recipient adoption of professional advice for strength of advice as the moderating variable

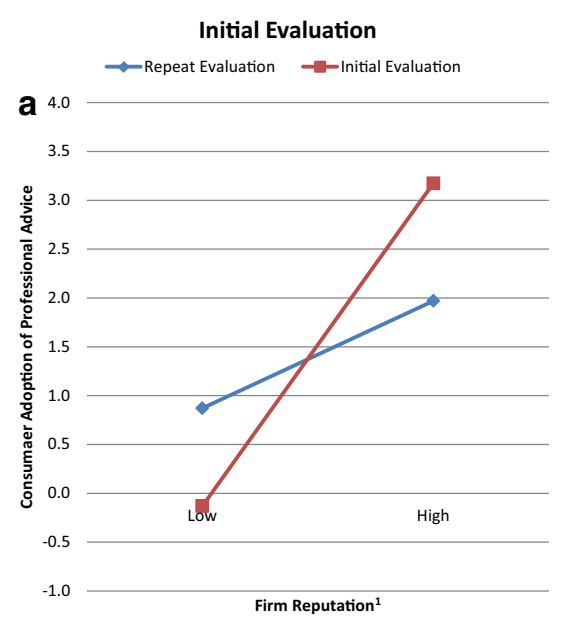

${ }^{1}$ Low and high firm reputation is defined as one standard deviation below and above the mean of the variable.

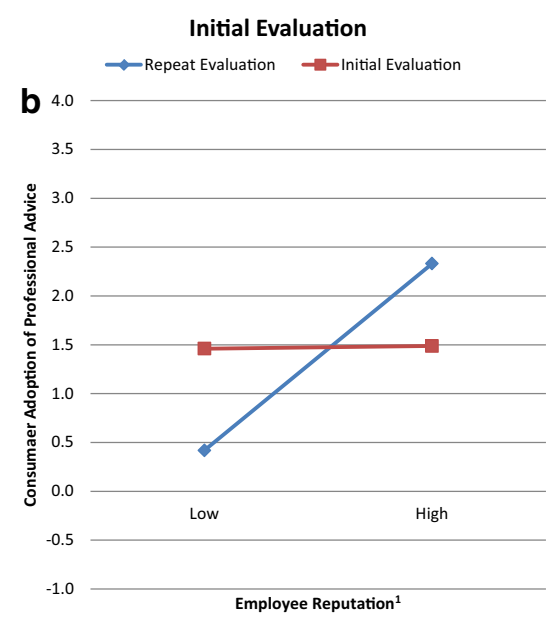

${ }^{1}$ Low and high employee reputation is defined as one standard deviation below and above the mean of the variable.

Fig. 2 a Plot of the relationship between firm reputation and recipient adoption of professional advice for initial evaluation as the moderating variable. b Plot of the relationship between employee reputation and recipient adoption of professional advice for initial evaluation as the moderating variable

We use the same approach and find that the positive association between firm reputation and recipient adoption of professional advice for repeat evaluations in Fig. 2a is statistically insignificant. In contrast, the positive association between employee reputation and recipient adoption of professional advice for repeat 
evaluations in Fig. $2 \mathrm{~b}$ is statistically significant. These results are consistent with our expectation that when recipients increase their reliance on employee reputation, they will decrease their reliance on firm reputation when reacting to repeat evaluations (Busemeyer and Townsend 1993; Khoury et al. 2013).

We also perform robust analyses to check whether the results in model 3 remain substantively similar with different measures of employee and firm reputations. We arrived at similar conclusions when employee reputation is measured using a dummy variable approach or when firm reputation is measured using the StarMine rankings.

In sum, we find evidence that several contextual factors influence the reliance that recipients place on firm and employee reputations when reacting to evaluation reports produced by professional service firms. Specifically, recipient reliance on firm (employee) reputation appears to be higher (lower) when the evaluation of an entity is an initial one rather than a repeated one. In contrast, recipient reliance on employee reputation increases with stronger recommendation or when the entity covered by the report has a business relationship with the firm producing the report. Overall, the effect of firm reputation on advice adoption is mostly positive and significant under the contingencies examined, whereas the effect of employee reputation exhibits more variation across the contingency conditions.

\section{Discussion}

Overall, our findings show that service recipients consider firm and employee reputations in deciding whether to adopt professional advice from a service provider. These results are consistent with past studies that highlight the importance of reputational assets (Dawar and Parker 1994; Parasuraman et al. 1985; Zajac and Westphal 1996). However, our findings contribute to past studies by providing empirical evidence that recipients distinguish between employee and firm reputations in the adoption decision. The results of this paper clearly highlight the pitfalls of past studies that erroneously use one reputation construct as a measure for the other (Clarke et al. 2007). Furthermore, the results indicate that the effect of employee reputation on advice adoption is more susceptible to contextual contingencies than is the effect of firm reputation, a finding that is not highlighted in current studies. To the best of our knowledge, our study is the first to report these empirical results about the contextual contingencies.

\subsection{Theoretical contributions}

We successfully apply and integrate RBT and signaling theory to explain the effects of firm and employee reputations on professional advice adoption, and the contingencies affecting the effects. First, RBT provides the conceptual tools to theorize the resources that potentially create firm- and employee-level reputations (Barney 1991; Dierickx and Cool 1989). The application of RBT in the context of professional advice adoption helps to tease out the high covered firm-specificity and 
low hiring-firm-specificity nature of employee reputation in comparison to firm reputation (Mikhail et al. 1997).

Second, our reasoning about the importance of quality signals to advice recipients in professional advice adoption adds to our understanding about the determinants of advice adoption, as extant research has not examined the role of quality signals in advice adoption. We argue that professional services are intangible and therefore, recipients look for quality signals when assessing the reliability of professional advice (Connelly et al. 2011). Our finding that advice adoption is influenced by firm and employee reputations supports this reasoning.

Third, while RBT enhances our understanding of the fundamental differences between firm and employee reputations, it does not provide a strong conceptual foundation to predict the contingencies under which recipients will rely on these reputations more, or less, when adopting the professional advice. To develop hypotheses about the contingencies, we supplement the insights of RBT with those of signaling theory. In particular, building upon the recommendations of Connelly et al. (2011), we incorporate the context of the signaling environment and the concept of signal fit to predict how recipient reliance on either reputation type is contingent on the type of report, the strength of the advice, and the presence of a business relationship between the service firm and the covered entity.

Fourth, drawing from the literature on the relationship between attention given to a decision criterion and usage of the criterion in decision-making (Roe et al. 2001), we argue that recipients who devote more attention to a quality signal place less emphasis on other signals in their quality judgment. Our examination of initial evaluation as a moderator supports this argument. We find that when the evaluation report on a covered entity is an initial rather than a repeated one, recipients rely less on employee reputation but more on firm reputation when adopting the advice of the report. This shift in emphasis suggests that when recipients perceive that some signals do not correlate well with the quality being signaled, recipients shift their attention to other signals, and subsequently pay greater emphasis on these signals in quality judgment. Therefore, this finding corroborates our premise about the relationship between attention received by a quality signal and its role in quality judgment.

\subsection{Managerial and policy implications}

Our study was conducted in the context of brokerage firms offering investment advice on the stocks of a listed firm. Such investment advice shares key similarities with other securities rating services. For example, similar to stock analysts, bond analysts examine the business prospects and financial well-being of the covered firms, and bond credit ratings agencies may also encounter potential conflicts of interest under certain circumstances. Therefore, our findings on stock recommendations can be relevant to providers and recipients of these rating services as well. Furthermore, to some extent, the findings may be applicable to other kinds of evaluation services that are provided primarily in the form of a report and do not require direct interactions between the professional and the advice recipient. Examples include auditing of financial statements, credit rating of countries and individuals, and accreditation of businesses. 
Our findings imply that the upper echelons of professional service firms ought to be aware that firm and employee reputations are two distinct constructs that may hold different significance for certain stakeholders. The effect of firm reputation on advice adoption is positive and significant regardless of the contingencies, except when the brokerage report is a repeated evaluation. Therefore, generally speaking, it is advantageous for brokerage firms to highlight their reputation in brokerage reports and when communicating with investors (e.g., their Web sites and newsletters). For example, they can show their performance ranking derived from surveys with investors or a third-party rating system (e.g., TipRanks). In contrast, while it is possible for professional service firms to "rent" the reputations of individual(s) to enhance their standing (Deutsch and Ross 2003), top executives of such firms should be cognizant that "rented" individual reputations may not matter much to specific stakeholder groups under certain circumstances. Understanding when employee reputation matters more to certain stakeholder groups contributes to better stakeholder management practices that may in turn generate higher profits for these firms. For instance, when the covered firms have business relationships with the brokerage firms, top executives of the brokerage firms should assign reputable analysts to the covered firms, given that recipients react more strongly to and in a manner consistent with the stock recommendations of these analysts. Such assignments may be justified by the economic value created by higher revenues from trading commissions for the brokerage firm when the recommendations favor the stocks in question. Furthermore, in the presence of business relationships, the names and profiles of reputable analysts should be shown prominently in the brokerage reports so as to fully exploit the reputation effect on recipients.

While rankings in investor/customer surveys provide a reputation measure, there are also other reputation measures that service firms and employees can tap into. For example, many analysts showcase their written analysis and expert opinions in a variety of social media platforms, including Twitter and popular financial blogs (Egger 2014). Readers can comment on, "like" or share the analysts' posts. They can also "follow" individual analysts for their posts through email alert, news feed, etc. The numbers of comments, "likes" and "followers" that analysts garner effectively indicate their popularity or online reputation. Furthermore, some financial blogs rank analyst contributors based on the popularity of their posts. For example, Seeking Alpha, a financial blogging site with approximately 8.4 million monthly unique visits, has a section highlighting "the most read authors by topic in the last 90 days" (Egger 2014). Such rankings can serve as another reputation measure. To promote investors' awareness of their reputation, analysts can highlight their performance along these measures in their profiles (e.g., LinkedIn profiles) or personal Web pages. Brokerage firms can also help promote awareness of analyst reputation by hyperlinking their corporate sites to these social media platforms.

Aside from service firms and employees, policy makers may also benefit from this study. Given that information on firm and employee reputations helps recipients separate credible recommendations from less reliable ones, policy makers may consider facilitating access to this information. For example, government or professional bodies may hyperlink their Web sites to sites that publish rankings of analysts and brokerage firms (e.g., the Institutional Investor and the TipRanks sites). Our findings also suggest that contextual factors (e.g., potential conflicts of interest, 
initial vs. repeated evaluation) affect recipients' usage of the reputation. Therefore, consistent with the practice and legislation in some countries, government or professional bodies should require analysts and brokerage firms to highlight in brokerage reports contextual details that affect investors' judgment. The need to disclose such details also applies to the auditing business in which potential conflicts of interest can bias professional judgment.

\subsection{Limitations and future research}

Our study was carried out in one sector (financial service) and one country (Singapore) only, thus limiting the generalizability of our findings. Future studies may examine the generalizability in other institutional settings or services (e.g., non-financial services or services involving interaction between employees and service recipients), and investigate other potential moderators as well. For instance, according to the GLOBE survey, Singapore's society is ranked fourth out of 61 countries with a score of 4.9 in societal institutional collectivism. In contrast, the U.S., where most studies on firm and individual reputations are conducted, is ranked in a lower band at the thirty-second position. Different scores in societal institutional collectivism may influence the relative importance that stakeholders place on individual and firm reputations, the latter of which is inherently collective in nature. Thus, future research may test the generalizability of our results by collecting cross-cultural samples. Such study also permits the examination of potential institutional effects on the value that stakeholders place on firm and individual reputations.

Another limitation is that we could not examine the cognitive rationale behind a recipient's choice to rely more or less on employee and firm reputations since our study uses archival data to test the hypotheses. For instance, it is not clear why we found that the presence of a business relationship and the strength of advice moderated the association between recipient adoption of professional advice and employee reputation, but did not moderate the association between the adoption and firm reputation. A better understanding of how contextual factors affect recipient reliance on firm and employee reputations as quality signals could be achieved by collecting recipients' verbal reports (Patton 1990). For example, by interviewing recipients in depth or asking them to list the thoughts that run through their heads, researchers can collect data that capture the cognitive processes and responses during recipient decision-making. Furthermore, experimental design can be employed in future research to establish the causality of the focal relationships involving firm and employee reputations. The experimental method allows manipulation of independent variables of interest (e.g., the two types of reputations and the contextual factors) and thus helps establish the internal validity of research findings.

\section{Conclusion}

In conclusion, this research identifies firm and employee reputations as two key factors affecting professional advice adoption. This paper distinguishes between service firm and employee reputations by their underlying qualities and applies the 
distinction to predict how service recipients utilize the two kinds of reputation differently when evaluating professional advice. Supporting the distinction, our empirical investigation shows that recipients' usage of employee reputation is more sensitive to contextual contingencies than is their usage of firm reputation. Our findings thus challenge the conventional wisdom that reputations bring enduring benefits for both firms and employees, and point to a need of separating firm reputation and employee reputation in studying reputation effects on professional advice adoption. Our findings also have implications for service providers with regard to promoting awareness of firm and employee reputations, and deploying reputable employees to cover particular entities. To policy makers, our research provides implications concerning initiatives aiming to enhance research coverage of stocks, facilitating public access to reputation information, and regulating service firms and employees to provide relevant contextual details in their recommendations. As our investigation is carried out in the financial sector of Singapore, we hope more research can be conducted on how the reputation effects take place for different services and contexts. Future research may also look into the cognitive rationale underlying recipients' reliance on a particular kind of reputation and the longer-term effects of reputations on recipients.

Acknowledgments This work was supported by Nanyang Technological University under Grant RCC7/ 2008/NBS.

\section{Appendix: Computation of abnormal returns (AR) to measure consumer adoption of advice in brokerage reports}

Bloomberg data was used to compute the AR in the financial-event study. Operationally, the AR is defined as the actual ex-post-return on the share price of a firm minus the normal return on day t, i.e., $\mathrm{AR}_{i t}=R_{i t}-E\left(R_{i t}\right)$, where $\mathrm{AR}_{i t}$ is the abnormal return on the share price for firm $i$ on event date $t, R_{i t}$ is the actual ex-postreturn on the share price for firm $i$ on event date $t$, and $E\left(R_{i t}\right)$ is the normal return on the share price for firm $i$ on event date $t$. The normal return, $E\left(R_{i t}\right)$, is defined as the expected return if the event of interest (i.e., the publication of a brokerage report) had not taken place, and is computed using a market model of the normal share price behavior. The market model is a statistical model that relates the return of any given share to the return of a specified market portfolio, i.e., $R_{i t}=\alpha_{i}+\beta_{i} R_{m t}+\varepsilon_{i t}$, where $\alpha_{i}$ is the intercept term, $\beta_{i}$ is the systematic risk of firm $i, R_{m t}$ is the rate of return on the Singapore All-Sing Equities Index, which tracks the returns of all SGX-listed equities, on date $t$, and $\varepsilon_{i t}$ is the error term.

The normal return around the event of interest was computed as follows. First, following McWilliams and Siegel (1997), we estimated the market model on a window that was prior to and did not overlap with the event window in which we expect the abnormal returns attributed to the target event to be observable. We set the estimation window at 200 trading days ending 10 days prior to the event window and defined the event window as a 2-day period that comprises 1 day prior to and the day of publishing the brokerage reports. After we had estimated the 
market model, we used the model parameter estimates to predict the normal returns for the 2 days in the event window. From these predicted values, we derived the ARs for the 2 days and summed the ARs up to arrive at the cumulative abnormal returns (CAR) over the event window.

\section{References}

Aiken LS, West SG (1991) Multiple regression: testing and interpreting interactions. Sage, Newbury Park Asquith P, Mikhail MB, Au AS (2005) Information content of equity analyst reports. J Financ Econ 75(2):245-282

Baldwin NS, Rice R (1997) Information-seeking behavior of securities analysts: individual and institutional influences, information sources and channels, and outcomes. J Am Soc Inf Sci 48(8):674-693

Barber B, Lehavy R, McNichols M, Trueman B (2001) Can investors profit from the prophets? Security analyst recommendations and stock returns. J Finance 56(2):531-563

Barney J (1991) Firm resources and sustained competitive advantage. J Manag 17(1):99-120

Berry LL (1980) Service marketing is different. Business 30(3):24-29

Bishop P, Megicks P (2002) Asymmetric information and strategic competition in estate agency. Serv Ind J 22(2):89-108

Bonaccio S, Dalal RS (2006) Advice taking and decision-making: an integrative literature review and implications for the organizational sciences. Organ Behav Hum Decis Process 101(2):127-151

Bosquet K, de Goeij P, Smedts K (2014) Gender heterogeneity in the sell-side analyst recommendation issuing process. Finance Res Lett 11(2):104-111

Boyd BK, Bergh DD, Ketchen DJJ (2010) Reconsidering the reputation-performance relationship: a resource-based view. J Manag 36(3):588-609

Busemeyer JR, Townsend JT (1993) Decision field theory: a dynamic-cognitive approach to decision making in an uncertain environment. Psychol Rev 100(3):432-459

Calderon-Monge E, Huerta-Zavala P (2014) Brand and performance signals in the choice of franchise opportunities. Serv Ind J 34(9-10):772-787

Clarke J, Khorana A, Patel A, Rau PR (2007) The impact of all-star analyst job changes on their coverage choices and investment banking deal flow. J Financ Econ 84(3):713-737

Clement MB (1999) Analyst forecast accuracy: do ability, resources, and portfolio complexity matter? J Account Econ 27(3):285-303

Coff RW (1999) When competitive advantage doesn't lead to performance: the resource-based view and stakeholder bargaining power. Org Sci 10(2):119-133

Connelly BL, Certo ST, Ireland RD, Reutzel CR (2011) Signaling theory: a review and assessment. J Manag 37(1):39-67

Cote J, Goodstein J (1999) A breed apart? Security analysts and herding behavior. J Bus Ethics 18(3):305-314

Dawar N, Parker P (1994) Marketing universals: consumers' use of brand name, price, physical appearance, and retailer reputation as signals of product quality. J Mark 58(2):81-95

Deutsch Y, Ross TW (2003) You are known by the directors you keep: reputable directors as a signaling mechanism for young firms. Manag Sci 49(8):1003-1017

Diefenbach RE (1972) How good is institutional brokerage research? Financ Anal J 28(1):54-60

Dierickx I, Cool K (1989) Asset stock accumulation and sustainability of competitive advantage. Manag Sci 35(12):1504-1511

Dimson E, Marsh P (1984) An analysis of brokers' and analysts' unpublished forecasts of UK stock returns. J Finance 39(5):1257-1292

Dodds WB, Monroe KB, Grewal D (1991) Effects of price, brand, and store information on buyers' product evaluations. J Mark Res 28(3):307-319

Efendi J, Files R, Ouyang B, Swanson EP (2013) Executive turnover following option backdating allegations. Account Rev 88(1):75-105

Egger BD (2014) Social media: strategies for investing. Adams Media, Avon 
Fang L, Yasuda A (2009) The effectiveness of reputation as a disciplinary mechanism in sell-side research. Rev Financ Stud 22(9):3735-3777

Firth M (1990) Auditor reputation: the impact of critical reports issued by government inspectors. RAND J Econ 21(3):374-387

Gillis JG, Earp MH (1979) Interpretations of professional conduct. Financ Anal J 35(2):10-12, 77-78

Goes JB, Park SH (1997) Interorganizational links and innovation: the case of hospital services. Acad Manag J 40(3):673-696

Groysberg B, Lee L-E (2008) The effect of colleague quality on top performance: the case of security analysts. J Org Behav 29(8):1123-1144

Holmes R (2006) So that's how they did it. Retrieved from http://rankingwatch.blogspot.sg/2006/09/sothats-how-they-did-it-for-some-time.html

Hong H, Kubik JD (2003) Analyzing the analysts: career concerns and biased earnings forecasts. J Finance 58(1):313-351

Huat TC, Lim J, Chen W (2004). Competing international financial centers: a comparative study between Hong Kong and Singapore. Institute of Southeast Asian Studies Conference. Retrieved from http:// bschool.nus.edu/SAW/Publications.aspx

Irvine PJ (2003) The incremental impact of analyst initiation of coverage. J Corp Finance 9(4):431-451

Irwin JR, McClelland GH (2001) Misleading heuristics and moderated multiple regression models. J Mark Res 38(1):100-109

Jackson AR (2005) Trade generation, reputation, and sell-side analysts. J Finance 60(2):673-717

Jeng S-P (2011) The effect of corporate reputations on customer perceptions and cross-buying intentions. Serv Ind J 31(6):851-862

Jennings MM (2005) Ethics and investment management: true reform. Financ Anal J 61(3):45-58

Kang E (2008) Director interlocks and spillover effects of reputational penalties from financial reporting fraud. Acad Manag J 51(3):537-555

Karpoff JM, Lott JR (2005) The reputational penalties for environmental violations: empirical evidence. J Law Econ 48(2):653-675

Khoury TA, Junkunc M, Deeds DL (2013) The social construction of legitimacy through signaling social capital: exploring the conditional value of alliances and underwriters at IPO. Entrep Theory Pract 37(3):569-601

Kozlenkova IV, Samaha SA, Palmatier RW (2014) Resource-based theory in marketing. J Acad Mark Sci 42(1): $1-21$

Kumar A (2010) Self-selection and the forecasting abilities of female equity analysts. J Account Res 48(2):393-435

Lee SM, Ribeiro D, Olson DL, Roig S (2007) The importance of the activities of service business in the economy: welcome to the service business. An International Journal. Serv Bus 1(1):1-5

Li S, Srinivasan K, Sun B (2009) Internet auction features as quality signals. J Mark 73(1):75-92

McWilliams A, Siegel D (1997) Event studies in management research: theoretical and empirical issues. Acad Manag J 40(3):626-657

Mikhail MB, Walther BR, Willis RH (1997) Do security analysts improve their performance with experience? J Account Res 35:131-157

Monroe KB, Dodds WB (1991) A research program for establishing the validity of the price-quality relationship. J Acad Mark Sci 16(1):151-168

Nelson R, Winter S (1982) An evolutionary theory of economic change. Harvard University Press, Cambridge

Olmedo-Cifuentes I, Martínez-León IM, Davies G (2013) Managing internal stakeholders' views of corporate reputation. Service Bus 8(1):83-111

Ozmel U, Reuer J, Gulati R (2012) Signals across multiple networks: how venture capital and alliance networks affect interorganizational collaboration. Acad Manag J 56(3):852-866

Palmatier RW, Houston MB, Dant RP, Grewal D (2013) Relationship velocity: toward a theory of relationship dynamics. J Mark 77(1):13-30

Parasuraman A, Zeithaml VA, Berry LL (1985) A conceptual model of service quality and its implications for future research. J Mark 49(4):41-50

Patton MQ (1990) Qualitative evaluation and research methods, 2nd edn. Sage, Newbury Park

Pil FK, Leana C (2009) Applying organizational research to public school reform: the effects of teacher human and social capital on student performance. Acad Manag J 52(6):1101-1124

Rabe-Hesketh S, Skrondal A (2008) Multilevel and longitudinal modeling using Stata. Stata Press, College Station 
Riley JG (2001) Silver signals: twenty-five years of screening and signaling. J Econ Lit 39(2):432-478 Roberts PW, Dowling GR (2002) Corporate reputation and sustained superior financial performance. Strateg Manag J 23(12):1077-1093

Roe RM, Busemeyer JR, Townsend JT (2001) Multialternative decision field theory: a dynamic connectionist model of decision making. Psychol Rev 108(2):370-392

Schijven M, Hitt MA (2012) The vicarious wisdom of crowds: toward a behavioral perspective on investor reactions to acquisition announcements. Strateg Manag J 33(11):1247-1268

Seiders K, Flynn AG, Berry LL, Haws KL (2015) Motivating customers to adhere to expert advice in professional services: a medical service context. J Serv Res 18(1):39-58

Siow LS (2002) Scrupulous conduct vital amid scandals. Business Times Singapore, Singapore

Sniezek JA, Schrah GE, Dalal RS (2004) Improving judgment with prepaid expert advice. J Behav Decis Mak 17(3):173-190

Spanjol J, Cui AS, Nakata C, Sharp LK, Crawford SY, Xiao Y, Watson-Manheim MB (2015) Coproduction of prolonged, complex, and negative services: an examination of medication adherence in chronically Ill individuals. J Serv Res 18(3):284-302

Stickel SE (1995) The anatomy of the performance of buy and sell recommendations. Financ Anal J 51(5):25-39

Wiles MA, Morgan NA, Rego LL (2012) The effect of brand acquisition and disposal on stock returns. J Mark 76(1):38-58

Yim CKB, Tse DK, Chan KW (2008) Strengthening customer loyalty through intimacy and passion: roles of customer-firm affection and customer-staff relationships in services. J Mark Res 45(6):741-756

Zajac EJ, Westphal JD (1996) Director reputation, CEO-board power, and the dynamics of board interlocks. Adm Sci Q 41(3):507-529

Zeithaml VA, Parasuraman A, Berry LL (1985) Problems and strategies in services marketing. J Mark 49(2):33-46 